\title{
ALAMSAKSA LAENSÕNADEST JOHANNES GUTSLAFFI GRAMMATIKA TAUSTAL ${ }^{1}$
}

\author{
Jüri Viikberg \\ Eesti Keele Instituut ja Tallinna Ülikool
}

\begin{abstract}
Kokkuvõte. Johannes Gutslaff oli Urvaste koguduse pastor (1641-1656), kes on läinud eesti kirjakeele ajalukku esimese lõunaeesti grammatika „Observationes grammaticae circa linguam Esthonicam" (1648) koostajana. Artiklis on võetud vaatluse alla tema keeleõpetuse saksa-eesti sõnastikuosa eesti vasted ja põhitähelepanu on koondatud alamsaksa laensõnade leidumisele. Väljasõelutud sõnad on rühmitatud vastavalt sellele, kas saksa märksõna tähendust on eesti keeles edasi antud alamsaksa laenu või omasõna abil. Jõutakse järeldusele, et Gutslaffi sõnakasutus on üheks indikaatoriks alamsaksa laensõnade tulekul eesti keelde. Veidi üle poole eesti sõnavastetest moodustavad alamsaksa laensõnad, millega on saksa märksõnade tähendust edasi andnud nii Gutslaff kui ka tema kaasaegsed. Teise poole moodustavad sellised eesti vasted, mille puhul Gutslaffi kaasaegsed eelistasid alamsaksa laensõnu, tema ise aga kas omasõnu või varasematest keelekontaktidest pärit laene. Silmas pidades Gutslaffi töö- ja elukohta Urvastes, on need omasõnavasted rühmitatud murdeleviku alusel: ühed on registreeritud eeskätt põhjaeesti murretest või laiemaltki, teised on iseloomulikud lõunaeesti murdeile, iseäranis Võru murdele. Lõpuks esitatakse vasted, mis on tõenäoliselt Gutslaffi enese loodud.
\end{abstract}

Märksõnad: alamsaksa laensõnad, eesti vana kirjakeel, lõunaeesti kirjakeel, 17. sajand, Johannes Gutslaff, keelekontaktid

DOI: http://dx.doi.org/10.12697/jeful.2013.4.3.11

\section{Sissejuhatus}

Sõnavara rikastamisest ning sõnalaenudest on sageli räägitud innovatsioonide kontekstis - teistel rahvastel leitakse olevat midagi uut ja teistsugust, mis tuleks tingimata kasutusele võtta, ja enamasti võetakse see miski käibele koos vastava nimetusega. See teisest keelest võetud nimetus a) võib jääda muutmata, b) seda võidakse suupärastada oma keele järgi või c) tõlkida oma keelde. Omas keeles vajalike sõnade kasutuselevõttu teistest keeltest nimetatakse üldiselt

1 Artikli kirjutamisel olen saanud tuge riiklikust programmist „Eesti keel ja kultuurimälu" (EKKM11-219) ning Uppsala ülikoolilt (külalisteadurina 2013. aasta kevadsemestril). 
laenamiseks ning neid sõnu laensõnadeks. Olgugi tegu (justkui) laenuks võetuga, ei ole „tagastamisjuhtumite” kohta siiski näiteid teada. Kui uus sõna kasutajaskonna poolehoidu ei leia, jäetakse see lihtsalt kõrvale. Nurisetud on küll selle üle, et laenamistega on liiale mindud ja et keelde on soetatud n-ö tarbetuid laene (vana kirjakeele puhul nt Liin 1968: 60), omakeelsetele vastevõimalustele vaatamata. Sageli on põhjuseks peetud lihtsalt tõlkija ebapiisavat keeletundmist.

Siinse kirjutise lähtealuseks on allakirjutanu andmebaas „Alamsaksa laensõnad eesti keeles" Eesti Keele Instituudi leksikograafide töökeskkonnas EELex, mis hõlmab 1000-1200 (kesk)alamsaksa keele kaudu etümologiseeritud laensõna. Laenude keeldetuleku aja ja leviku näitlikustamiseks on sinna aastatel 2011-2013 kogutud selliseidki andmeid nagu sõna varaseim teadaolev üleskirjutus, esinemus vanas kirjakeeles, olulisemates leksikonides, eesti murretes ning sugulaskeeltes ja ka läti keeles (nt Hinderling 1981, Raun 1982, Raag 1987, Koponen 1998, Keem 1998, SSA). Taolise taustamaterjali olemasolu võimaldab võrrelda alamsaksa laensõnade leidumust eri murretes ja keeltes ning märgata nende ilmumist omaaegsete autorite leksikonidesse.

16.-17. sajandi kirjakeelest näitestiku valimisel torkas silma, et Johannes Gutslaffi grammatika sõnastikuosas „Nomenclator Germanico-Esthonicus" leiduv eesti sõnavara erineb ta kaasaegsete (nt G. Müller, H. Stahl, J. Rossihnius, H. Göseken) omast. Eripära tuleneb kindlasti juba sellest, et tegu on lõunaeesti keele käsitlusega põhjaeesti käsitluste kõrval. Samas tundus esmamulje põhjal, et kuigi 17. sajandit võib pidada ka laensõnatulva ajastuks, ei ole Gutslaff olnud väga varmas saksa keelest uusi laensõnu introdutseerima. Siinse kirjutise eesmärk olekski välja selgitada, mil määral leidub eesti keeles teada olevaid alamsaksa laensõnu Gutslaffi sõnastikus saksa märksõnade vastetena ja kuivõrd on ta seal tollaseid laensõnu korvanud kas (lõuna)eesti omasõnade või juba varasematest laenukihtidest pärit sõnadega. Gutslaffi sõnavasteid on vaadeldud eesti 16.-17. sajandi kirjasõna taustal.

Johannes Gutslaff oli Urvaste koguduse pastor (1641-1656), kes on läinud eesti kirjakeele ajalukku esimese lõunaeesti grammatika „Observationes grammaticae circa linguam Esthonicam” (1648) koostajana. Siinne ülevaade tugineb grammatika faksiimileväljaande eestikeelsele tõlkele „Grammatilisi vaatlusi eesti keelest” (1998), mille autor on Marju Lepajõe. Faksiimileväljaande aluseks oli Eesti Kirjandusmuuseumis talletatav ainus säilinud eksemplar. Sõnastik (41 lk, u 1800 sõna) ei ole kahjuks täielik, lõpp alates wieden-sõnast on puudu (sh wi- kuni wü- ja kõik $z$-algulised sõnad), võimalik, et puudub koguni poogna jagu materjali. 
Grammatika eesti keelde tõlkinud Marju Lepajõe lausub järelsõnas (Lepajõe 1998: 285): „Johannes Gutslaff on eesti keele ja kultuuri ajaloos õnnelikus olukorras. Teda on uuritud suhteliselt vähe ja ainult eesti keele seisukohalt, mistõttu ta on tõlgendustega koormamata." Siinne kirjutis loodab Gutslaffi tõlgendustele - eesti keele seisukohalt - mõningast lisa pakkuda ning haakuda varasemate publikatsioonidega alamsaksa laensõnade kohta 16. ja 17. sajandi eesti kirjakeeles (nt Ariste 1940, Ariste 1963, Liin 1964, Liin 1968).

Järgnev sõnavalik tugineb Gutslaffi grammatika sõnastikuosale, millest on võetud vaatluse alla saksa märksõnade eesti vasted. Materjali valimisel ning esituse liigitamisel on olnud põhikriteeriumiks sõnade päritolu. Jaotise 2 moodustavad alamsaksa laensõnad, millega on saksa märksõnade tähendust edasi andnud nii Gutslaff kui ka tema kaasaegsed. Jaotise 3 moodustavad sellised saksa märksõnade eesti vasted, kus Gutslaffi kaasaegsed on eelistanud alamsaksa laensõnu, tema ise aga kas omasõnavara või hoopis varasematest kontaktidest saadud sõnu. Silmas pidades Gutslaffi töö- ja elukohta Urvastes, on jaotise 3 sõnavasteid rühmitatud murdeleviku alusel: 3.1 sõnad on registreeritud eeskätt põhjaeesti murretest (või ka laiemalt), 3.2 sõnad on iseloomulikud lõunaeesti murdeile, iseäranis Võru murdele. Jaotise 3.3 moodustavad sõnad, mille Gutslaff on võinud ise moodustada. Vajaduse korral viidatakse eri osades paiknevate sõnade seostele.

\section{Alamsaksa laen saksa märksõna eesti vastena}

Selle rühma moodustavad keelde lisandunud laenud (sh kristlik leksika, kus alamsaksa keelel on olnud oluline toetaja ning kaasvahendaja roll), millega on kas täidetud mõistelisi tühikuid või lihtsalt täiendatud eesti keele sõnavara. Osa sõnu (tähisega $\dagger$ ) leidub üksnes võõrsõnadena meie vanimas kirjakeeles, mitte aga hiljem.

Siinses kirjutises on Gutslaffi saksa-eesti sõnastikust saanud - küll tublisti väiksemas mahus - ümberpööratud eesti-saksa sõnastik. Sõnaartiklis on esikohal eesti märksõna (amet) tänapäeva ortograafias, järgnevad eesti (Ammit /i) ning saksa sõna ('Ampt') originaalkujul (Gutslaffil Ampt Ammit/i) ja eestindatud grammatika leheküljenumber (lk 206). Laensõnade päritoluandmed on võetud etümoloogialeksikonidest ja uurimustest-artiklitest, 16.-17. sajandi kirjakeele näited aga vana kirjakeele alastest (allika)publikatsioonidest (vt allikate loetelu artikli lõpus).

altar - Altar $/ i$ 'Altar' (lk 206) < lad altāre ning kasks altar 'Altar' altari peel (Koell 1535); Altarÿ, Altare, Altarist (Müller 1600-1606); sest Altarist (Rossihnius 1632); Altar, -i (Göseken 1660) 
amet - Ammit /i 'Ampt' (lk 206) < kasks am(m)et 'Amt'

Añeti, Ammeti, Añetist (Müller 1600-1606); Ammeti perrast

(Rossihnius 1632); Ammet, Ammetist (Stahl 1637); Ammet, -i

(Göseken 1660)

arst - Arst $/ i$ 'Arst' ${ }^{2}$ (lk 207) < kasks arste 'Arzt'

Reÿede artzte '[haavaarstide]' (Awerbach 1589); se eike Arst (Müller

1600-1606); sedda arsti abbi (Rossihnius1632); Arst, arstist (Stahl

1637); Arst, $-i$ 'Arzt; Barbier; wund Arzt (chirurgus)' (Göseken 1660)

höövel - Höfli 'Höfel' (lk 219) < kasks hovel 'Hobel'

höfel, höflist (Stahl 1637); Höwel (Göseken 1660)

ingel - Engel / $i$ 'Engel' (lk 212) < kasks engel 'Engel'

Engel (Koell 1535); ni palyo englit (Boierus 1587); neet Englit

(Müller 1600-1606); pöha Engel (Rossihnius 1632); Engel, Englist

(Stahl 1637); Jngel; Engli koggodus 'engelschaar' (Göseken 1660)

$\dagger$ junkru - Junckr /o 'Jungfraw' (1k 220) < kasks junkvrowe 'Jungfrau'

puchtast iunkrust (Völcker 1585); puchtast Iunckrost (Rossihnius

1632); neizit 'Jungfrau' (Göseken 1660)

kaal - Kale 'Schale'; Kâl /a 'Wage (libra)' (lk 234; 245) < kasks schale

'Schale; Wage'

Kaal, -i; Kahli 'Schale (Wageschale)' (Göseken 1660)

kann $^{4}$ - Kanne 'Kanne' (lk 221) < rts kanna, kasks kanne 'Kanne'

Kan, kannuft (Stahl 1637); wessikañi 'Gies-Kann'; kanno körw

'Handhabe (an der Kannen)' (Göseken 1660)

kants - Kantze 'Schantze' (lk 234) < kasks schanze 'Schanze'

Kantz, kantzist (Stahl 1637); Kantzi; Kantz (Göseken 1660)

karp - Karpekene 'Schachtel' < kasks karpe 'Kiste'

Karpekenne 'Karpe (Schachtel)'; karpikenn 'büchs (darin man etwas leget)'; Karpeken 'Lädelein (Schrein)' (Göseken 1660)

kee - Kädi; Ahila 'Kette' (lk 221) < kasks kede 'Kette'

Raudkedide siddes (Müller 1600-1606); Kehd, -i (Göseken 1660)

2 Saksa märksõnaks on sõnastikus alamsaksa Arst (pro ülemsaksa Arzt), mis osutab, et üleminek ülemsaksa kirjakeelele ei olnud 17. sajandil veel lõppenud.

3 neitsi-sõna on Gutslaff kasutanud piiblitõlkes: Netzu, ütz Junckr sahb hendas sahma (Gutslaff 1647-1657: 218).

4 Rootsi keelest ( $<$ rts kanna) pärit $u$-tüveline sõna esineb kirjakeeles ja murretes (R eP M), alamsaksa keelest (< kasks kanne) pärit $i$-tüveline sõna esineb murretes (I TaPõ Hel T V). 
keiser - Keiser / $i$ 'Keiser' (lk 221) < kasks keiser 'Kaiser'

Keÿser (Müller 1600-1606); selle Keysrille (Rossihnius 1632); Keifer, keifrift (Stahl 1637); Keijser, -i; Kayser (Göseken 1660)

kekk 'narr' - Jeck /e 'Hoffnarr'; Jeck /e 'Narr' (lk 219; 228) < kasks geck' 'Geck' keckide Sadtuße wasta (Müller 1600-1606); Geck 'Narr' (Stahl 1637); Keck, Jeck 'Geck' (Göseken 1660). Vt julge osas 3.3; vrd hulluth Narrit (Müller 1600-1606); needh jeckit ninck nahrit (Rossihnius 1632); nar, narrift (Stahl 1637); Narr (Göseken 1660); narr-sõna Gutslaffil ei leidugi

kelder - Keller / $i$ 'Keller' (lk 221) < kasks keller, kelder 'Keller' Kelleri sees (Müller 1600-1606); Keller, kelrist (Stahl 1637); Keller, -i (Göseken 1660)

kinkima - kinckma /e 'schenken (donare)' (1k 234) < kasks schenken 'schenken' meile schencknut (Müller 1600-1606); kincksit temmale kulda (Rossihnius 1632); kenckima, kenckin, kencksin, kenckinut (Stahl 1637); kinckima (Göseken 1660)

klaas - Klâsick 'Glaß' (lk 216) < kasks glas 'Glas' üx Vws Glaß|acken (Müller 1600-1606); ütte klasi Salwi kahn; ütz klasick (Rossihnius 1632); klahs, klahsist; lebbi öhe klafi (Stahl 1637); Laas, -i (Göseken 1660)

klint - Kiwwi-Klindt 'Felß' (lk 213) < kasks klint, klinte 'Fels, felsige Anhöhe'

kool - Kôli 'Schule' (lk 236) < kasks schole 'Schule'

Schoel, Schole, Scholi (Müller 1600-1606); kohli sissen (Rossihnius 1632); Kooli; Kohli (Göseken 1660)

korv - Korw /e 'Korb' (lk 222) < kasks korf 'Korb' korwi sissen (Rossihnius 1632); korw, korwift (Stahl 1637); Korw, -i (Göseken 1660)

krae - Kraje 'Krage' (lk 223) < kasks krage 'Kragen' kraj, krãift (Stahl 1637); Kraije; Kraij (Göseken 1660)

kriit - Krîte 'Kreide' (lk 223) < kasks krite 'Kreide' Rijhti; rihti walgke 'weisse kreide' (Göseken 1660)

5 Näide omaaegsest $g$ hääldusest $j$-na; sõna levikule $k e k k$-kujul eesti kirjakeeles ja murretes (eP Ran Krl Lei Lut) on ilmselt (hilisem) ülemsaksa Geck 'keku, keigar' kaasa aidanud. 
kroon - Krôni 'Krone' < kasks krône 'Krone'

Cron; Kronith (Müller 1600-1606); ütz krohn (Rossihnius 1632);

krohn, krohnift (Stahl 1637); Rooni (Göseken 1660)

kuub 'mantel' - Kûb /a; Mantel /i 'Mantel ${ }^{6}$ ' (lk 226) < kasks schube

'Schaube'

hallÿ kuwe kaas (Müller 1600-1606); Kuhb 'Rock' (Stahl 1637);

Kuhb 'ein Rock' (Göseken 1660). Vt mantel 2. osas

käärid - Kêre 'Schere' (lk 234) < kasks schere 'Schere'

kehr, kehrist (Stahl 1637); Keer, -i 'Scheer'; Lichtkeer 'Lichtscher' (Göseken 1660)

köök - Köki 'Küche' (lk 223) < kasks kōke 'Küche'

köke; kö(h)ki, köeck (Kullamaa käsikiri 1524); Köeck, -i; köhki

(Göseken 1660)

laadik 'laegas' - Ladick 'Lade' (1k 223) < kasks lade 'Lade'

Ladick, ladickaft (Stahl 1637); Ladick (Göseken 1660)

lamp - Lampe 'Lampe' (224) < kasks lampe, sks Lampe

lampide kahn (Rossihnius 1632); Lampi (Göseken 1660)

latt - Rôde / Latte 'Latte' (lk 224) < kasks latte 'Latte'

Lat, lattist (Stahl 1637); latti (Göseken 1660). Vt roode osas 3.2

leer 'laager' - Läer / $i$ 'Läger' (lk 224) < kasks leger 'Lager' ütte lehri (Rossihnius 1632); Leer, leerift (Stahl 1637); leer, -i; Leer 'Läger (Feldläger)' (Göseken 1660)

lood 'raskusmõõt' - Lôti 'Kugel' (lk 225) < kasks lode 'Lot' löhd, löhdift 'Kugel; Loth' (Stahl 1637); löhd, -i; löhdi 'Lodt (Kugel)'; kax loot 'Zwey looht (uncia)' (Göseken 1660)

lunt 'lambitaht; (süüte)nöör)': Lunti 'Lunte' (lk 225) < kasks lonte, lunte lunti 'Lunte' (Göseken 1660)

lust - Lusti 'Lust' (1k 225) < kasks lust(e) 'Lust'

Lusti kaas (Müller 1600-1606); omma lusti (Rossihnius 1632);

füddame lufti kahs (Stahl 1637); lusti, -i (Göseken 1660)

lõõr - Löhri 'Rahre, Arteria' (lk 231) < kasks rồre 'Röhre'

mantel - Kûb /a; Mantel / $i$ 'Mantel' (lk 226) < kasks mantel, sks Mantel se Risti|kuwe, echk se Risti|mantle (Müller 1600-1606); omma Mantli

6 Saksa Mantel-sõna vasteks on Gutslaffil nii kuub kui ka mantel, alamsaksa laenud tõenäoliselt mõlemad; kuub-sõna on murretes levinud laiemalt (R eP M T Urv) kui mantel (eeskätt eP). 
(Rossihnius 1632); mantle; weema kuub 'Regen-Mantel' (Göseken 1660). Vt kuub 2. osas

mirr 'mürr' - Mirra 'Mirre' (lk 227) < kasks mirre 'Myrrhe' Myrrhe (Rossihnius 1632); myrrit (Stahl 1637); myrrit; mijrrit (Göseken 1660)

mold - Moldi 'Mulde' (lk 227) < kasks molde 'Mulde' molli (Göseken 1660)

mölder - Möller /e 'Müller' (lk 227) < kasks moller, molner 'Müller' moller (Göseken 1660)

munk - Munck /e 'Münch' (lk 227) < kasks monk 'Mönch' nente Mukade (Müller 1600-1606); sest Muhka ächk Babsti hulckast (Rossihnius 1632); munck, munckaft (Stahl 1637); Munck (Göseken 1660)

müts - mütz 'Mütze' (lk 92) < kasks mütze 'Mütze, Kopfbedeckung' mütz 'Mütze'; Mützeken 'Bortichen' (Göseken 1660)

müür - Müri 'Mawr' (lk 226) < kasks mûrr(e) 'Mauer' Mühr (Müller 1600-1606); lebbi se mühri (Rossihnius 1632); mühr, mührift (Stahl 1637); mühr, -i; mühr (Göseken 1660)

naaber - Nâber 'Nachbar' (lk 228) < kasks nâber 'Nachbar' meddÿ naber (Müller 1600-1606); truwit Nabrit (Rossihnius 1632); Naber, Nabrift (Stahl 1637); Naaber (Göseken 1660)

nunn - Nunne 'Nonne' (lk 229) < kasks nunne 'Nonne' Nunne; Nunne wera 'die Süster Pfort'(Göseken 1660)

nööp - Nôp /e 'Knopff' (lk 222) < kasks knôp 'Knopf' nöhp, nöhpift (Stahl 1637); nöhp, -i; nöhp (Göseken 1660)

nöör - Nörick /o 'Schnur' (lk 236) < kasks snôr(e) 'Schnur' eike Richt|schnor (Müller 1600-1606); nöhr (Göseken 1660)

ohver - offr $/ i$ 'offer ${ }^{7}$, (lk 229) < kasks offer 'Opfer' lebbÿ se aino Offere (Müller 1600-1606); se offri mannu (Rossihnius 1632); Offer, offrift (Stahl 1637); opper; oppri watz 'Opffer kuchen' (Göseken 1660)

orel - Orgel 'Orgel' (lk 229) < kasks orgel 'Orgel' orgel (Göseken 1660)

7 Saksa märksõnaks on sõnastikus alamsaksa offer (pro ülemsaksa $O p f e r$ ), mis osutab, et üleminek ülemsaksa kirjakeelele ei olnud 17. sajandil veel lõppenud. 
paar - Pâr 'Paar' (1k 230) < kasks pâr 'Paar'

veel pare, Kax ... Iütlust (Müller 1600-1606); ütz par raghwast

(Rossihnius 1632); pahr, pahrift (Stahl 1637); paar, -i (Göseken 1660)

paarid 'sarikad' - Pâri 'Sparren auffm Hause' (lk 239) < kasks spare 'Sparre' paarit 'Spar auffm Hause'(Göseken 1660)

†paavi 'paabulind' - Pâwi 'Pfaw' (lk 230) < kasks pawe 'Pfaw' (+ lind) pawluhni hend 'Pfawenschwantz' (Göseken 1660)

pann - Panni 'Pfanne' (lk 230) < kasks panne 'Pfanne' Pan, pannift (Stahl 1637); pann, -i (Göseken 1660)

pasun - Passîn /a 'Tromete' (lk 242) < kasks bas(s)une 'Posaune' pasunie ka (Boierus 1587); Paßunadde kaas (Müller 1600-1606); passuna kahn (Rossihnius 1632); ommat paffunat (Stahl 1637); passun, -a 'Posaun'; Passuna 'trommete (tuba)' (Göseken 1660)

†pekk 'korjandustaldrik; kauss'-Bicken /e 'Becken' (lk 207) < kasks becken 'Becken' ütte Becki sisse (Rossihnius 1632); Pecki; Kessi pecki 'Handbecke'; wohdi pecki 'Nacht-Scherbel' (Göseken 1660)

†penning '(kaela)raha' - Kuldpenning 'Ducatus' (lk 90) < kasks penni(n)k 'ein Münzstück jeder Art; Pfenning' üche kaunÿ Kul|Peñinge (Müller 1600-1606); Kuldpenninck 'Goldgülden; Ducaten' (Göseken 1660). Vt teng osas 3.1

pigi - Pick 'Pech' (lk 230) < kasks pik 'Pech' Pörgku Pick̈̈ (Müller 1600-1606); picki (Göseken 1660)

piilar - pîler 'Pfeiler' (lk 230) < kasks pîlere, pîlre, pilar 'Pfeiler' Piler, pihlrift (Stahl 1637); Pijler; pijhler, -i (Göseken 1660)

piin - Pîna / Wallu 'Peine' (lk 230) < kasks pîne, pîn 'Pein' sest pörko|hauwa pinast (Rossihnius 1632); pihn, pihnast (Stahl 1637); pijhn, -a; Pijhn ninck wallo 'Qual' (Göseken 1660)

pood '(müügi)putka'-Bôdi 'Bude' (lk 209) < kasks bôde 'Bude' se tolli pohti sissen (Rossihnius 1632); Poedi; Poodi-Mees 'budensitzer' (Göseken 1660)

pull - Pulle 'Bulle'; Pullekenne 'Stier' (lk 209; 240) < kasks bulle 'Bulle' pull; Sonn (Göseken 1660)

pung 'tengelpung' - Pung /e 'Geldbeutel' < kasks punge 'Beutel, Säckchen' pung (Rossihnius 1632) 
püss - Püsse 'Büchse' (lk 209) < kasks busse 'Büchse' suhre Püßide kz (Müller 1600-1606); Püs, püssift (Stahl 1637); Püß; Püssi (Göseken 1660)

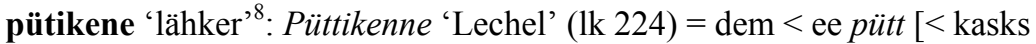
bütte 'Bütte']

vrd Leckel, -i (Göseken 1660) < asks Lechel, Lecher 'Lägel'

pütt - Pütt /o 'Tonne' (lk 242) < kasks bütte 'Bütte'

Sadda pütti (Rossihnius 1632); putt, püttiken 'bütte/Gefäs' (Göseken 1660)

raad - Raht /e 'Raht, Senatus' (lk 231) < kasks rât 'Rat' außull Rhade, Isandee (Ametivanne 1570); Rads Isandette ehen (Awerbach 1589); selle Rattile (Rossihnius 1632); Rahd, rahdift (Stahl 1637); Raad, -i (Göseken 1660)

raam - Ramm 'Bâre, Todten-Bâre' (lk 207) < kasks rame, ramen 'Rahmen' rahm, rahmi/t (Stahl 1637); Raam, - $i$ 'Bahr darauff man etwas träget'; Sitta Raam; Surnu Raam (Göseken 1660)

renn - Rönni 'Rinne' (lk 232) < kasks renne 'Rinne'

Rönni 'Rinne'; wee rönni 'plumpe (antlia)' (Göseken 1660)

rent - rent $/ e^{10}$ 'heure' $(1 \mathrm{k} 219)<$ kasks rente 'Rente' rent, rentift (Stahl 1637); Renti 'heure/Rente'; Renti 'zins (usura)' (Göseken 1660)

ringutama - ringutama 'sich recken' (lk 231) < kasks wringen 'sich winden', sks ringen

ringutama; welia ringutama 'Ausrecken den Leib' (Göseken 1660)

roos - Roseninni 'Rose' (lk 232) < kasks rose, sks Rose

Roside poel (Müller 1600-1606); taiwane rohs; Rohse, rohsift (Stahl 1637); Roese; Rohse; Rosanini 'rose (flos)' (Göseken 1660)

ruun - Rûn /e 'Wallach' (lk 245) < kasks rūne 'Wallach' ruhn (Stahl 1637); Ruhn, -a (Göseken 1660)

röst 'rest' - Rösti 'Röste' (lk 233) < kasks röste 'Rost' Palawa Roste pcele (Müller 1600-1606); Roft, roftift 'Röft' (Stahl 1637); Rosti 'Roste' (Göseken 1660)

8 pütt ja lähker on mõlemad keskalamsaksa laenud, levinud nii põhja- kui ka lõunaeesti murdeis; nende kõrval esineb Gutslaffil ka lännik-sõna - Lennik 'Bütte' (lk 224).

9 Tõenäoliselt on renn-sõna rõnn-variant kirjas edasi antud $\ddot{o}$-ga.

10 rent ja üür on mõlemad alamsaksa laensõnad, levinud põhja- ja lõunaeesti murdeis. 
röövel - Röwel /e 'Mörder' (lk 227) < kasks rồver 'Räuber'

kurrÿ tegkia ninck Röwer (Müller 1600-1606); ütz kurja|teggia n. rowel (Rossihnius 1632); röhwel, röhwlift (Stahl 1637); Röewel 'Räuber'; röhwel 'mörder (sicarius)' (Göseken 1660)

rüütel - Rütel /e 'Reuter' (lk 232) < kasks ruter 'Ritter'

Rühtel 'Reutter'; Rütel 'reiter (sessor)' (Göseken 1660)

saag - Saje 'Sage (Serra)' (lk 233) < kasks sage 'Säge'

fai, faift (Stahl 1637); Saij; Sai 'Sage (serra)' (Göseken 1660)

safran - Sappran 'Saffran' (lk 233) < kasks safrân, saffarân 'Safran' Sappran 'Saffran (crocus)' (Göseken 1660)

salv - Salw /e 'Salbe' (lk 233) < kasks salve 'Salbe'

ütte klasi Salwi (Rossihnius 1632); üx waimolick falw (Stahl 1637);

Salw, -i; Silma rocht 'Aug Salbe' (Göseken 1660)

seep - Sêpi 'Seiffe' (lk 238) < kasks sêpe 'Seife'

se sehp sest mösckjast (Rossihnius 1632); Seep, seepift (Stahl 1637);

Seep, -i (Göseken 1660)

selts 'selts(kond)' - Seltz /i 'Gefaehrte' (lk 215) < kasks sel(t)schop

'Gesellschaft'

kuria Selße siße (Müller 1600-1606); henesse Selsix wotta;

Selsyweliet; temma the seltsit (Rossihnius 1632); feltz, feltzift; teije

feltzix (Stahl 1637); Seltz, -i (Göseken 1660)

siid - Sîde 'Seide' < kasks side 'Seide'

Sÿdit (Müller 1600-1606); sinno sidi|reiwat (Rossihnius 1632); fidi ridet (Stahl 1637); Sijhdi (Göseken 1660)

sikk - sick /a; oinas 'Bock' (lk 208) < kasks sicke(n) 'Zicke' mitte Sicko; Sicka|werd (Müller 1600-1606); sick, sickest (Stahl 1637); Sick 'bock; Ziegen bock' (Göseken 1660). Vt oinas osas 3.1

sinep - Sinnip /e 'Senff' (lk 238) < kasks sennep, sennip 'Senf'

Sinnapi; Sinnip 'Senff (sinapi)' (Göseken 1660)

taaler - Wannathaler 'Thalerus' (lk 90) < kasks da(a)ler 'Thaler' tuhat Talerit echk Kuldpenningit (Müller 1600-1606); wanna Thaler 'ReichsThaler' (Göseken 1660)

tall - Talli 'Stall (Equile)' (lk 240) < kasks stal 'Stall' sen Talli siddes (Müller 1600-1606); Tal, tallift (Stahl 1637); Tall, -i (Göseken 1660)

tamm - Thamm /e 'Damm' (lk 210) < kasks dam 'Damm' Thamm, - $i$ 'Dam'; wescki Sulgk 'mühlen dam' (Göseken 1660) 
tekk - Tecki 'Decke' (1k 210) < kasks decke 'Decke'

teck, teckift (Stahl 1637); Tecki; hobbose Tecki; wohdi tecki (Göseken 1660)

tiik - Dîck /e 'Teich' (lk 241) < kasks dîk 'Teich'

tijhki; Tijhki (Göseken 1660)

trehtel 'lehter' - Trechter / Wallim /i 'Trechter' (lk 242) < kasks trechter 'Trichter'

trichtel 'Trechter'; wallim 'trichter (infundibulum)' (Göseken 1660).

Vt valim osas 3.2

trepp - Reppe 'Treppe' (lk 242) < kasks treppe 'Treppe'

Trep, treppift (Stahl 1637); Rep, -i; Reppi 'Stuffe/Treppe' (Göseken 1660)

troon - Trôn /e 'Thron' (lk 242) < kasks trôn, sks Thron

troni sissen (Rossihnius 1632); throni ehs (Stahl 1637); troon, -i

'Trohn'; Jergk 'thron' (Göseken 1660)

troost 'trööst': Trôst / Röhm /a 'Trost' (lk 242) < kasks trôst 'Trost'

Trost nĩck röÿmu (Müller 1600-1606); Troh/t, [trohst]ift (Stahl 1637); troost, -i; Rohst 'trost (solatium)' (Göseken 1660). Vt rõõom osas 3.3

trumm - Rumm /e 'Tromel' (lk 242) < kasks trumme 'Trommel' Rumme 'Paucke/Trommel'; Rumm 'trummel (tympanum)' (Göseken 1660)

truu - Truiw /i 'Getrew'; Truw 'Trew' (lk 216; 242) < kasks truwe 'treu' truw Iumala Sullane (Müller 1600-1606); truwit üllembät (Rossihnius 1632); truw, -i (Göseken 1660)

tuvi - Tuiwe 'Taube' (lk 241) < kasks duve 'Taube'

katz nohrt tuwit (Rossihnius 1632); öhe duwikeffe (Stahl 1637);

tuikenne; Tuwikenne (Göseken 1660)

tükk 'kild, tükk' - paa tück 'scherbel' (lk 234) < kasks stucke 'Stück' kax löhikest tücki (Müller 1600-1606); ütte tücki kützetüt kalla (Rossihnius 1632); üx muldatück; Tück, [tück]ift (Stahl 1637); Tück, -i; mulda tück 'erd-klos'; Sabba-tück 'schwantz-stück' (Göseken 1660)

vaat - Wâti 'Faß; Vaß'11 $(\mathrm{lk} 212,243)<$ kasks vat 'Fass'

kax ... Vate (Müller 1600-1606); waht, wahtift (Stahl 1637); waat, -i (Göseken 1660); asti 'Fas/Geschir'; Waahti 'Fas (dolium)' (Göseken 1660)

11 Sõnastikus esineb saksa märksõna kahel kujul: Faß (lk 212) ja Vaß (lk 243). 
vammus - Wammus 'Wambs' (lk 245) < kasks wam(me)s 'Wams' wammusse kahn (Rossihnius 1632); Wammus (Göseken 1660)

vangis - Wangis 'Gefangen' (lk 215) < kasks vangene 'Gefangene' üx waine Wangk (Müller 1600-1606); ütte wangi (Rossihnius 1632); wangk, wangkift; wangkix wotma 'Gefangen nehmen' (Stahl 1637); wangk; wangki kodda 'der gefangenen haus' (Göseken 1660)

viin 'vein' - Wina 'Wein' (lk 246) < kasks wîn 'Wein' wagkewa Wina (Müller 1600-1606); se Leiba ninck Wina (Rossihnius 1632); Wihn, wihnast (Stahl 1637); wijhn, - a (Göseken 1660)

võll - Wölli 'Welle' (lk 246) < kasks welle 'Welle' welboom 'welle in der Mühlen'(Göseken 1660)

võlsma 'valetama': Wölsckma /e 'Lügen' (lk 225) < kasks valsch 'falsch'; levinud lõunaeesti murdeis

võlss = vale 'valsk': Wölsk /a 'Lügen' (lk 225) < kasks valsch 'falsch'; levinud lõunaeesti murdeis

võlv - Wölvi 'Gewölb' (lk 216) < kasks welve 'Gewölbe, Welle' Wölw, wölwift (Stahl 1637); wölw (Göseken 1660)

värk - Werck /e 'Arth / artific' (lk 206) < kasks werk 'Werk' werck (Göseken 1660). Vt töö osas 3.1

äädikas - Ettickas 'Essig' (1k 212) < kasks etik, etek 'Essig' ätiket ächk wihna sappi (Rossihnius 1632); Ettickas, ettickaft (Stahl 1637); Ettikas, - a (Göseken 1660)

Nimestikust puuduvad võimalike laenudena kirn ja viiul, sest Gutslaffi sõnastikus on saksa Kerne (1k 221) ja Geige (lk 215) järel tühi koht. kirn-sõna (võimalik rootsi ja/või alamsaksa laen) mainivad ka Stahl (1637) (kirn, kirnuft) ja Göseken (1660) (Kirn), viiul-sõna ( $<$ kasks viole 'Violine; Geige') pole aga registreeritud teisteltki 17. sajandi autoreilt (vrd Kijhgi 'Geige' Gösekenil). Nimestikku pole võetud ka saksa Jude vastet Judalinne (1k 220) ${ }^{12}$, sest eeldatava tähenduse 'Juudamaa elanik' asemel on see sõna eesti murretes üldtuntud kui 'põrguline, kurivaim'.

Gutslaffi sõnastikus leiduvad keskalamsaksa laenud (103 sõna) näikse hästi sobituvat teiste 17 . sajandi autorite sõnakasutusega. Suurima ühisosa leiame ootuspäraselt olevat Gösekeniga, oli ju Gösekeni sõnastik (u 10000 sõna) ka vähemalt viis korda Gutslaffi omast mahukam. Tollaseid alamsaksa laensõnu, mida teistelt autoritelt

12 Vrd Judaliste Kool 'Juden Schul' (Göseken 1660). 
pole registreeritud, leidub Gutslaffi grammatikas neli (klint, lõorr, võlsma, võlss $)^{13}$.

\section{Omasõnavara eelistamine}

Paljud 17. sajandiks eesti keelde ning tollaste autorite teostesse jõudnud alamsaksa laensõnad Gutslaffi grammatika saksa-eesti sõnastikus ei kajastu. Ta on eelistanud nende asemel võtta eesti vasteks kas omasõna, juba varasema laenuna omaksvõetu või on tuletanud sõnavaste ise. Niisiis pole laenud tulnud sageli mitte tühjale kohale, vaid on ilmunud keeles olemas olevate sõnade kõrvale. Oma sõnavara eelistamist alamsaksa laenule võib täheldada ülejäänud märksõnade puhul (osa neist pole tänapäeval küll arhaismidena enam arusaadavad). Parema ülevaate saamiseks on neid eesti sõnavasteid rühmitatud murdeleviku alusel: 3.1 murretes laiemalt levinud sõnavara ning 3.2 lõunaeesti murdesõnavara. Murdesõnade levikuandmed pärinevad eesti murrete sõnaraamatust (EMS), väikesest murdesõnastikust (VMS), Andrus Saareste mõistelisest sõnaraamatust (EKMS) ja Eesti Keele Instituudi murdekartoteegist (EKI MK). Jaotise 3.3 moodustavad arvatavalt Gutslaffi enese pakutud sõnavasted.

\subsection{Laiema levikuga omasõnavara}

Alljärgneva rühma moodustavad põhjaeesti murretes (S L K I) või veel laiemalt levinud sõnad. Kõiki siinseid Gutslaffi sõnu pole murdekeelest (selles tähenduses) registreeritud, kuid enamikku on siiski olnud võimalik tuvastada murdeleksikonide ja -kartoteegi abil.

eri - Erri $/ a^{14}$ 'Dienst' (lk 210), vrd teenistus < kasks dênst 'Dienst' Jumala Thenistusse (Müller 1600-1606); minnu thenistust (Rossihnius 1632); deniftus, denistuffe/t (Stahl 1637); tenistus 'Dienst/Hülff'; teenistus 'Verdienst (meritum)' (Göseken 1660)

13 Siinkohal tuleks rõhutada, et grammatikas leiduv on siiski vaid osa autori sõnavarast. Heaks näiteks on hiljuti publitseeritud piiblitõlge (Gutslaff 1647-1657 [2013]). Sealt annaks siinsesse alamsaksa laenude sõnastikku lisada veel 44 sõna, millest kaht (köömen, seekel) pole ka Gutslaffi kaasaegseilt registreeritud.

14 eri (g erja) pole murdekeelest registreeritud, kuid eri (g eri) 'tegevus, toiming' on teada saarte ja läänemurdest (EMS I: 780; EKMS II: 1285). eri-sõna tagant võib aimuda isegi 'äri'-tähendust, vrd Werckeltag 'Erripäiw' (lk 246), s.t töö- ehk äripäev. 
erjama - erjama 'dienen (servire) ${ }^{15}$ (lk 210), vrd teenima $<$ kasks dênen 'dienen'

temale ... tienut (Boierus 1587); tenidt Iumala (Müller 1600-1606); teddä thenimä (Rossihnius 1632); denima, denin, denifin, deninut (Stahl 1637); teenima 'Dienen; verdienen (mereri)' (Göseken 1660) murdelevik: pole registreeritud

hirs - Hirs /e 'Balcke' (lk 207), vrd palk< kasks balke 'Balken' sedda Balcki (Rossihnius 1632), Palck, palckift (Stahl 1637), Palck, -i; palcki mets, palcki puh (Göseken 1660) murdelevik: $\operatorname{irs}(s),(h) i r s$ Lüg S L I eL

kaitsma - kaitzma 'wachten' (lk 245), vrd vahtima $<$ kasks wachten 'wachen, aufpassen' wachtima (Göseken 1660) murdelevik: `kaits|ma eP T V, -me M; `kaitsema R S Ha Jä I

kalits - Kalliche 'Tasche' (lk 241), vrd task ${ }^{16}<$ kasks taske 'Tasche' tascki 'tasche' (Göseken 1660) murdelevik: kalits R L K Trm Trv, kalit Lei

kallis - kallis 'werth' (lk 246), vrd väärt < kasks wert, sks wert kuß tibbo Wert on (LiiviTalu 1550); röhmu weerdt (Müller 1600 1606); ep olle mitte werth (Stahl 1637); wehrt, -i (Göseken 1660) murdelevik: 'kallis R, kallis(s), kallis(s) eP eL

karv - Karw /a 'Farbe' (lk 212), vrd värv < kasks verwe 'Farbe' kui werrest farb (Rossihnius 1632); farw, farwift (Stahl 1637); punnane warw 'röthe (rubedo)'; rohhtne Warw 'Grünspann' (Göseken 1660)

murdelevik: karv $\mathrm{R}$ eP eL

kaunis - kaunis 'schmuck' (lk 236), vrd mukk< kasks smuk 'schmuck' muck 'Schmuck'; muck 'hübsch, schön' (Göseken 1660) murdelevik: 'kaunis R, kaunis S L Ha Jä I, kauniss eL

kihl - kichlas 'Pfand (pignus)' (lk 230), vrd pant < kasks pant 'Pfand' Pant, [pant]ift (Stahl 1637); pant, -i (Göseken 1660) murdelevik : kihl 'pant' Juu VJg Se; kihlad 'käsiraha' Kuu Lüg Vig JMd Koe VMr Trm Plt KJn

15 teenima-sõna on Gutslaff kasutanud oma piiblitõlkes: Rahgwat thenikut Sinulle; Omma möhka pähl saht Sinna ellada, ninck Sinnu weljelle thenida (Gutslaff 1647-1657: 115, 116).

16 task on alamsaksa, tasku aga rootsi laensõna; Gutslaffil esinevad kalits (Tasche, $1 \mathrm{k}$ 241) ja karman (Beutel, lk 208) on mõlemad vene laensõnad, kalits on levinud põhjaeesti murdeis, karman üle maa. 
koger - Kogr /o 'Karrauß' (lk 221), vrd karus < kasks karusche, karusse

'Karausche'

Karruhs; karuß '[Karausch]' (Göseken 1660)

murdelevik: koger L VIPõ M T, kogṍr V, kogri S I

komme - Kombe 'Weise (modus) ${ }^{17}$ (lk 246), vrd viis < kasks wis(e) 'Art und Weise'

wijsi 'Art/Weise'; wijsi 'Art/Gewohnheit' (Göseken 1660)

murdelevik: komme eP M TLä, kommõ V, ‘kombe R Hi, ’kombõ V

laul - Laul /o 'Psalm' (lk 231), vrd salm < kasks salme 'Psalm'

Psalmit ninck Lauluth (Müller 1600-1606)

murdelevik: laul Sa L Ha VlPõ eL, ’aulu R, laal I, loul Sa Hi

lihunik - Lehaneck 'Schlächter' (1k 235), vrd †lahter < kasks slachter 'Schlachter'

Lachter, $-i$ 'Schlachter'; lachter 'metzger (Fleischer)' (Göseken 1660) murdelevik: lihunik Sa L K I M T, lihonik V, lihunikku R

liisk - Lîsk /a 'Loß' (lk 225), vrd loos < kasks lot, lôt 'Loos' lot, lottist (Stahl 1637); lotti 'Los (fors)' (Göseken 1660) murdelevik: liisk $\mathrm{R}$ eP eL

maja - Maja 'Herberge' (lk 218), vrd häärber < kasks herberge 'Herberge' se Herbergi sisse (Rossihnius 1632); Herpergi (Göseken 1660)

murdelevik: maja 'elamu’ R eP eL

mesileib - Messileib /a 'Pfefferkuch' (lk 230), vrd piparkook $<$ kasks

pepper-koke 'Pfefferkuchen'

peperkohck 'pfefferkuch' (Göseken 1660)

murdelevik: mesileib Ha Kod TaPõ Har

mõistma - mõistma (intelligere); tähele pannema (notare) 'mercken'

(lk 227), vrd märkama < kasks merken '(auf)merken'

merckada (Müller 1600-1606); ter̃a merckap (Stahl 1637). Vt tähele

panema osas 3.1

murdelevik: 'mõist|ma eP T V, -me M, 'muistama $\mathrm{R}$

narm - Narm /e 'Fleck' (lk 213), vrd plekk < kasks plecke 'Fleck'

se werri Christussest - essi ilma|fleckit (Rossihnius 1632)

murdelevik: pole registreeritud

oherdi - Oherith 'Bohr' (lk 208), vrd puur < kasks bōr 'Bohrer'

oherdi 'Bohr' (Stahl 1637); ohherdim 'Bohrer'; Rattaste ohherdim

17 viis-sõna on Gutslaff kasutanud oma piiblitõlkes: olli sell Mahsundijal ütz wihse (Gutslaff 1647-1657: 285). 
'Gros bohr' (Göseken 1660)

murdelevik: oherd(i) eP M T, ohõrd V, uherd R

oinas - oinas; sick /a 'Bock' (lk 208), vrd pukk< kasks buck, bock 'Bock'

Puck (Göseken 1660). Vt sikk 2. osas

murdelevik: oinas eP, 'oinas $\mathrm{R}$, oinass $\mathrm{eL}$

pada - padda 'Pott' (lk 231), vrd pott ${ }^{18}<$ kasks pot 'Topf, Pott'

katla echk Potte sides (Müller 1600-1606); ütte pot|seppa (Rossihnius

1632); pott, - $i$ (Göseken 1660)

murdelevik: pada $\mathrm{R}$ eP eL

pang - Panj /e 'Eimer' (lk 211), vrd ämber < kasks emmer, ammer

'Eimer'

ember, embreft (Stahl 1637); Ember, -i (Göseken 1660)

murdelevik: pang $\mathrm{R}$ eP eL

parv - parw /a 'Prahm' (lk 231), vrd praam < kasks prâm 'Prahm'

prahm 'Färe (ponto)' (Göseken 1660)

murdelevik: parv, paŕv $\mathrm{R}$ eP eL

pärandama - perrandama 'erben' (lk 212), vrd ärvima < kasks erven

'erben'

ervima; se Pattu erwinuth (Müller 1600-1606)

murdelevik: pärandama Sa Muh L Jä VlPõ, perandama VNg Jõh Iis, peränd|ämä Kuu Kod T V, -eme M

raamatunahk - Ramato Nachk /a 'Pappier' (lk 230), vrd paber < kasks $\operatorname{pap}(p) \hat{\imath} r$ 'Papier'

rahmato nachk (Stahl 1637); ramato nachk / papijr 'Papier (charta)'

(Göseken 1660)

murdelevik: pole registreeritud

salv - Salv /e 'Kaste' ${ }^{19}$ ' (lk 221), vrd kast < kasks kaste 'Kasten'

Kasti 'Kaste'; kasti '[Gefängnis]'; hullkasti 'tollhaus' (Göseken 1660)

murdelevik: salv, saĺv R L K I M T, saĺb Lä, sali S Pä

siil - sîl /o 'Geren im Kleide’ (lk 215), vrd käär(ima) < kasks scheren

'abschneiden, zerschneiden'

Rihde Keer, $-i$ 'gewand Scher' (Göseken 1660)

murdelevik: siil eP eL, 'siilu $\mathrm{R}$

18 Leidub liitsõna osana Gutslaffi piiblitõlkes: ostsit neihnde ehs ütte pottseppa (Gutslaff 1647-1657: 285).

19 kast-sõna tähistas tollal pigem vanglat. 
soon - Son /e 'Ader (Vena)' (lk 206), vrd aader < kasks âder(e) 'Ader' ader, adrift (Stahl 1637), Ader, - $i$ 'Ader'; werri Sohn 'Blut-Ader'; 'PulsAder' (Göseken 1660) murdelevik: soon, suon R eP, suuń eL

surmarohi - Surmarocht / $u$ 'Gifft' (lk 216), vrd kihvt ${ }^{20}<$ kasks gift 'Gift' gift (Stahl 1637); Kifft, -i; Surma Rocht 'Gifft' (Göseken 1660) murdelevik: 'surma- Lüg, surma- Tõs, sorma|rohi Käi

tee - Teh 'Reise' (lk 232), vrd reis 'teekond' < kasks reise 'Reise' se Te echk Reise pcele (Müller 1600-1606); Reisi 'Reise' (Göseken 1660) murdelevik: tee, tie $\mathrm{R} \mathrm{eP}$, tii $\mathrm{eL}$

teng '(kaela)raha' - Teng /a 'Pfenning' (lk 230), vrd †penning < kasks penni(n) $k$ 'ein Münzstück jeder Art; Pfenning' üche kaunÿ Kul|Peñinge (Müller 1600-1606); Kuldpenning 'Ducaten' (Göseken 1660). Vt penning 2. osas murdelevik: teng, teńg ‘väiksem rahaühik’ Hlj VNg Kse K I M TLä, ting $\mathrm{S}$ Mih Puh $\mathrm{V}$, ‘tinga $\mathrm{R}$

tuba - Tuba / Tarre 'Saal' (1k 233), vrd saal < kasks sāl, sâl, sks Saal suhre plastritut Sahli (Rossihnius 1632); Suhr tubba 'Saal' (Göseken 1660). Vt tare osas 2.2 murdelevik: tuba 'elu-, rehetuba' R eP M TLä

tunnikell 'päikesekell' - Tunni Kella 'Uhr' (lk 244)', vrd uur < kasks ûr(e) 'Stunde; Uhr' Tund 'Stunde (hora)'; tunni kell 'sonnenVhr (solarium)' (Göseken 1660) murdelevik: registreeritud on tunnipakk: Lüg S L Kod eL

tähele panema - tähele pannema (notare); mõistma (intelligere) 'mercken' (lk 227), vrd märkama < kasks merken '(auf)merken' merckada (Müller 1600-1606); teña merckap (Stahl 1637).

Vt mõistma osas 3.1 murdelevik: tähele pan|ema $\mathrm{R}$ eP T, -eme $\mathrm{M}$, tähile `pan $(d) m a \mathrm{~T} \mathrm{~V}$

töö - Töh 'Werck' (lk 206), vrd värk< kasks werk 'Werk' werck 'Werck' (Göseken 1660). Vt värk 2. osas murdelevik: töö, tüö R eP, tüü $\mathrm{eL}$

tüli - Tüld / $e^{21}$ 'Larm' (lk 224), vrd lärm < kasks allarm, allerm 'Lärm' Lermi (Göseken 1660) murdelevik: tüli VNg Lüg eP TLä, tülü Kuu Vai M Võn San V

20 mürk-sõna tähistas tollal terast, vrd lk 240: Stahl Mürck /e.

21 tüld-tüvega sõnadest on murdeist registreeritud vaid tülditama 'tüütama' Jõh (EKI $\mathrm{MK})$, seetõttu on siin eelistatud tüli-sõna. 
vaba - wabba 'frey (liber)' (lk 213), vrd prii < kasks vrî 'frei'

frÿ echk vabba (Müller 1600-1606); Wryherr, -i 'Freyherr'

(Göseken 1660)

murdelevik: vaba $\mathrm{R}$ eP eL

ülekohus 'unreht': üllekohus 'Unrecht' (lk 232), vrd unreht < kasks

un-recht, sks Unrecht

Valsch ninck Vnrecht (Müller 1600-1606)

murdelevik: üle|kohus R S Jä Iis KLõ, -kohos L Ha Kod, -kohuss M T, $-k u h u s s \mathrm{~V}$

Peale siin esitatud eesti sõnade leidub sõnastikus hulk selliseidki sõnavasteid, mille kõrvale on (hiljem) kasutusele tulnud alamsaksa laensõnad, mida pole veel registreeritud Gutslaffilt ega teistelt 17. sajandi autoreilt. Toodagu siin eraldi välja juhud, kus saksa märksõna vasteks võiks eeldada alamsaksa laensõna (nt mukkima), kuid kus Gutslaff alamsaksa laenu kasutanud ei ole (on ehitama). Gutslaffi sõnavaste on sulgudes kirjakeelse sõnakuju järel:

ehitama (ähhitama) 'ehtima' pro mukkima ( $<$ kasks smucken '(aus)schmücken'), emand (Emmand /a) pro proua ( $<$ kasks vrouwe 'Frau'), hall (Halli /a) 'hall loom' pro kimmel (< kasks schimmel 'Schimmel'), hõõruma (höhrema) pro riivima (< kasks rîven 'reiben'), kõrb (kerp /e) pro pruun (< kasks brûn 'braun'), laskma (laskma /e) pro puurima (< kasks bōren 'bohren'), leem (Lêm /e) pro supp (< kasks supen 'schlürfen'), maarjajää (Maria Jaeh) pro alun ( $<$ kasks alûn 'Alaun'), maitsma (maitzma) pro mekkima (< kasks smecken 'schmecken'), mõõtma (möht$m a)$ pro vaagima ( $<$ kasks wagen 'wagen'), ots (otz /a) pro pits $(<$ kasks spitse 'Spitze'), piit (pîth /a) pro post ( $<$ kasks post 'Pfost'), pärdik (Pertike) pro ahv (< kasks affe, sks Affe), pöid (pöid /o) pro velg $(<$ kasks velge 'Felge'), pügama (püggema) pro käärima ( $<$ kasks scheren 'aufscheren'), püssirohi (püssi Rocht /u) pro pulber ( $<$ kasks pulver 'Pulver'), selge (selg /e) pro klaar ( $<$ kasks klâr 'klar'), sile (Silli) pro klatt ( $<$ kasks glat, sks glatt), sõitma (seitma /a) pro reisima ( $<$ kasks reisen 'eine Reise machen'), sõna viima (Sönna wîma) 'teatama' pro meldima $(<$ kasks melden 'melden'), taplus (Tapplus) pro lahing ( $<$ kasks slachtinge 'Schlacht'), tapma (tappema) pro lahtima ( $<$ kasks slachten '(Vieh) schlachten'), telg $($ Telg $/ e)$ pro ass ( $<$ kasks asse 'Achse'), tina (Tinna) pro plii $(<$ kasks blī 'Blei'), tähendama (tähendama, signare) pro märkima (< kasks merken 'mit einer Marke, einem Merkmal versehen'), tühja pajatama (tühu pajatama) pro praalima ( $<$ kasks prâlen 'prahlen'), veeretama (wêritama) pro rullima ( $<$ kasks rullen, rollen 'rollen'), viht (Wicht $/ u$ ) pro punt $(<$ kasks bunt 'Bund'), võidma (woidma) pro määrima (< kasks smeren 'schmieren'). 


\subsection{Lõunaeesti murdeile (sh Võru murdele) iseloomulik sõnavara}

Järgnev sõnarühm koondab omasõnavara, mida Gutslaff on eelistanud alamsaksa laensõnadele ja mille leviku kese paikneb lõunaeesti murretes või ka otseselt Võru murdes.

hank 'konks' - Hangk /o 'Hake' (lk 217), vrd haak < kasks hâke 'Haken' Haaki; haaki 'hake (am kleide)'; haak 'Hake am Kessel' (Göseken 1660) murdelevik: ank San Võn, hank V

häötämä 'läbi lööma' - hähwtma /a 'prassen' (lk 231), vrd prassima < kasks brassen, prassen 'prassen' praffima, Praffin, praffifin, praffinut (Stahl 1637); prassima; prassya 'Schlemmer; Pancketirer' (Göseken 1660)

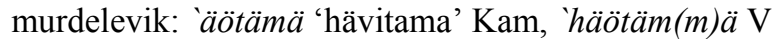

kaltsad - Kalczi ‘Hosen' (lk 219), vrd püksid < kasks bükse, büxe 'Beinkleid, Hosen'

Püxit 'Büxen (Hosen)'; püxit 'Bein kleider' (Göseken 1660) murdelevik: kal(t)sad Jaa L VIPõ; kaltsa, kal(d)sa M T, kalsa ${ }^{\text {? V }}$

karits 'kopsik; kulp'-Karritz 'Becher',22 (lk 207), vrd peeker < kasks beker 'Becher' Picker, - $i$ 'Becher'; picker 'trinck geshier' (Göseken 1660) murdelevik: karist $\mathrm{V}$

kasuksepp 'köösner': Kassucksepp 'Kürschner' (lk 223), vrd köösner $<$ kasks körs(e)ner(e) 'Kürschner' Körsner 'kürschner' (Göseken 1660) murdelevik: pole registreeritud ${ }^{23}$

kirikisand - kirckisand 'Pastor' (1k 230), vrd pastor < lad pastor, kasks pâstor 'Pastor' Pa.[stor] (Rossihnius 1632) murdelevik: kiriksand L Ha T, kerik-, kerk|esänd T V

kistavars 'telg, varb'-Kistawars 'Spille' (lk 239), vrd pill < kasks spille 'Spille, Spindel' pilli kaihl 'Hals an der MühlenSpille' (Göseken 1660) murdelevik: kistavar's 'keps; kedervars' Kod Hel T V

22 peeker-sõna on Gutslaff kasutanud oma piiblitõlkes, nt Minna - anni sedda Bickrit Pharao kettehe (Gutslaff 1647-1657: 171).

23 Leidub nt Saareste sõnaraamatus (kasuksepp ‘köösner’ EKMS III: 588). 
kütsmä 'küpsetama'- kützma / $u$ 'braten' (lk 209), vrd praadima < kasks braden 'braten' pradida (Müller 1600-1606), küpsendama 'braten' (Göseken 1660) murdelevik: küdsä|mä T V, -me M

kütse 'küps'-Kuetz le 'Brate' (lk 209), vrd praad < kasks brade 'Braten' pradiwarras (Stahl 1637); Praadi 'Brate'; küps 'Brate'; küpse ward 'BratSpes'; praadi pann 'Bratpfan' (Göseken 1660) murdelevik: küdse, küdsä $\mathrm{M} \mathrm{T}$, kütse, 'kütse T V

küünlalang - Künala Lang 'Tacht' (lk 241), vrd taht < kasks dacht 'Docht' sen pollewa tachti (Müller 1600-1606); tacht, tachtift (Stahl 1637); Tacht, -i; kühnla tacht, -i; tachti-löng 'Dachtgarn' (Göseken 1660) murdelevik: 'küündle lank Se

lapjo - Lapja 'Schauffel' (lk 234), vrd kühvel < kasks schuffele 'Schaufel' Küffel, küfflist (Stahl 1637); Küffel (Göseken 1660) murdelevik: lapi 'labidas' M, 'lapju M T, 'lapjo T V

lõupeni 'lõukoer'-Löiwi Penni ${ }^{24}$ 'Löwe' (lk 225), vrd lõvi < kasks louwe 'Löwe'

Louwit (Müller 1600-1606); löuw (Rossihnius1632); nende leuwide (Stahl 1637); Loiwkoijr; löwkoijar (Göseken 1660) murdelevik: lõupeni Krk Hel Har Lut

mõrsja - Morsi /a 'Braut' (lk 209), vrd pruut < kasks brût 'Braut' üx Brudt (Müller 1600-1606); Pruhdt, -i; morsi 'Braut' (Göseken 1660) murdelevik: 'morsja, 'mõrsi $\mathrm{R}$, 'mõrsja $\mathrm{eL}$

mõtstuvi - Mötztuiwi 'Turteltaube' (lk 241), vrd turteltuvi < kasks turtelduve 'Turteltaube' ütte pahri turtel|tuwit (Rossihnius 1632); Saxa mah keggi

'TurtelTaube' (Göseken 1660) murdelevik: mets|tuvi Lüg IisR IisK Trm, -tui Sa Muh L Juu KuuK ViK VlPõ, mõtstuvi Hel Ran ${ }^{25}$

penisitt - Pennißitt /a 'Schwefel' (lk 237), vrd väävel < kasks swevel 'Schwefel'

Schweuel (Müller 1600-1606); Weffel; wewel, wewlit 'schweffel (sulphur)'; KoiraSitt 'schweffel (sulphur)' (Göseken 1660) murdelevik: pole registreeritud ${ }^{26}$

24 lõupeni on lõukoera lõunaeesti vaste, liidetud alamsaksa esi- ja eesti järelosast $(<$ kasks louwe + ee koer/peni) nagu ka nt paabulind (< kasks pâwelûn + ee lind); vrd paavi 2. osas.

25 Sõna levikuala on (olnud) tõenäoliselt laiem, kui nähtub murdearhiivi andmeist.

26 Teada on vaid kasutusest sõimusõnana (Nõo Har). 
põrkapund 'laevanael' - Pörkopund /a 'Schiffpfund' (lk 235), vrd kippund < kasks schippunt 'Schiffspfund'

Kippund 'Schippfund' (Göseken 1660) murdelevik: põrka-, põrkõ|pund $\mathrm{V}$, perk- KJn Hls Krk, pärk|pund Vll Aud

rahu - Rahow /a 'Nieren' (lk 229), vrd neer < kasks nêre 'Niere' temmast nehrost (Rossihnius 1632); Neer / ne(h)r (Stahl 1637); neerit (Göseken 1660) murdelevik: rahu S VIPõ eL, rauh VId

roode - Rôde / Latte 'Latte' (1k 224), vrd latt < kasks latte 'Latte' Lat, lattist (Stahl 1637); latti (Göseken 1660). Vt latt 2. osas murdelevik: $\operatorname{roodjas}(s), \operatorname{rood}(m)$ ass 'latt, teivas' Hel Võn V

saurohi - Sauwrocht /u 'Weyrauch'27 (1k 246), vrd viiruk < kasks wî-rôk 'Weihrauch' wyroki tohma (Rossihnius 1632); wirock (Stahl 1637); wijrohk (Göseken 1660) murdelevik: liitsõna pole registreeritud, kuid sau 'suits' on Võru murdesõna

sepp - Sepp /e 'Hefe' (lk 218), vrd pärm < kasks berme 'Hefe'

Perme (Müller 1600-1606); parm; Parm, - $i$ 'Barm (Hefen)' (Göseken 1660) murdelevik: sepp Saa Kod MMg Äks SJn Vil eL

tare - Tuba / Tarre 'Saal' (lk 233), vrd saal< kasks sāl, sâl, sks Saal suhre plastritut Sahli (Rossihnius 1632); Suhr tubba 'Saal' (Göseken 1660). Vt tuba osas 3.1 murdelevik: tare 'tuba, maja' R Saa Kod T, tarõ V

tsigaliha - Zigga Leha 'Speck von Schwein’ (lk 239), vrd pekk< kasks speck 'Speck' pecki (Göseken 1660) murdelevik: tsiga T V; tsialiha Rõn San Krl Se

valim 'lehter' - Trechter / Wallim /i 'Trechter' (lk 242), vrd trehtel < kasks trechter 'Trichter' trichtel 'Trechter'; wallim 'trichter (infundibulum)' (Göseken 1660). Vt trehtel 2. osas murdelevik: valim $\mathrm{M}$, vallim $\mathrm{V}$

27 viiruk-sõna on Gutslaff kasutanud oma piiblitõlkes: weihit temmalle Kostit: Kulda, wihrokit n. mÿrrhe (Gutslaff 1647-1657: 221). 
vang - Wango 'Henge' (lk 218), vrd hing < kasks henge 'Hänge'

hingit 'Hengen an einer Thür' (Göseken 1660)

murdelevik: vang 'sang, käepide' eL

vanik 'pärg'-Wannick /o 'Kranz' (lk 223), vrd krants < kasks kranz 'Kranz' ütte krantzi (Rossihnius 1632); krantz, krantzist (Stahl 1637); Rantzi (Göseken 1660)

murdelevik: vanik T V, vańnik Trm Ksi San, vaanik Lai M

vasar - Wassar /a 'Hammer' (lk 217), vrd haamer < kasks hamer 'Hammer'

Hañere kz (Müller 1600-1606); Hammer, -i; Wassar 'Hã̃er'

(Göseken 1660)

murdelevik: vasar R S M T, vassar eL

vatsk 'kook' - Watsa 'Kuche' (lk 223), vrd kook < kasks koke 'Kuchen'

Kohck, kohckist (Stahl 1637); Koock, -a; Kohk (Göseken 1660)

murdelevik: vatsk Hel T V

vislamari 'kirss'-Wissila Marri 'Kirsch’ (1k 221), vrd käsper < kasks

kersebere 'Kirsche'

Karsberi marri (Stahl 1637); Karsbeer marri (Göseken 1660)

murdelevik: visla(k)puu mari 'kirss’ Urv Har Rõu Vas Se

Peale jaotises 3.2 mainitud lõunaeesti sõnade on sõnastikus veel sõnavasteid, mille kõrvale on küll hiljem lisandunud alamsaksa laensõnu, kuid mida pole registreerinud ei Gutslaff ega ta kaasaegsed. Järgnevas rühmakeses on Gutslaffi sõnavaste esitatud märksõna järel sulgudes ja seejärel osutatud murdelevilale:

herits (Herritz 'Schelm') ${ }^{28}$ - Nõo Võn Ote V - pro kelm (< kasks schelm 'Schelm'); hernetõbi 'rõuged' (Herne többe 'Pocken') ${ }^{29}-\mathrm{V}$ - pro pokad $<$ kasks pocke, poche 'Blatter, Bustel'; kooljakirst (Kôlje Kirst /o 'Sarck') $)^{30}$ - Khk Nõo Har Se - pro sark (< kasks sark 'Sarg'); käber 'korts' (Kebbarick 'Faltte') - V - pro volt (< kasks volde 'Falte'); langalõim (Langelöim /o 'Haspell') - Hel Kam V - pro haspel (< kasks haspel 'Haspel, Weife'); nilbe 'libe; sile' (nilb /e 'glatt, lubricus') - Iis Kod Ksi Hel T V - pro klatt (< kasks glat, sks glatt); saibas(s) 'teivas' (Saibas 'Pfahl') - San V - vrd paal (< kasks pâl 'Pfahl'); tsagama (zaggema 'hacken') - Hel Kam Ote Rõn San V - pro hakkima (< kasks hacken, sks hacken).

28 Gösekenil herrise töh 'schelm stück'

29 Gösekenil hirne többe 'pocken'

30 Gösekenil Surnukirst 'Sarch; sandapila' 
Sellesse rühma jäi paigutamata röärääk (Röarähk /e 'Schnepffe') Trv Krk Puh San V - vrd nepp (< kasks sneppe, snippe 'Schnepfe'), sest Gutslaffil on rukkirääk (sks Wachtelkönig) ja nepp (sks Schnepfe) ilmselt eksituse tõttu vahetusse läinud.

\subsection{Gutslaffi enese arvatavad sõnavasted}

Alamsaksa laensõnade asemele ja/või kõrvale (nt kekk, troost) näikse Gutslaff esitanud ka omapoolseid sõnavasteid, mida murdekeelest ega teistelt autoritelt pole registreeritud.

hagu pro meig (Hack /o 'Mey'), vrd Meykuh 'Mey (majus)' (Göseken $1660)<$ kasks mei, meig 'der Monat Mai; grüne Zweige von Birken zum Pfingstfest'

julge (julck /e 'keck'). Vt kekk 2. osas

kodunik pro pürjel (Koddoneck / $u$ 'Bürger'), vrd meidt .. Iumala Börrilix, Koddakundasex .. technut (Müller 1600-1606) < kasks börger(e), börgêre 'Burgmann, Bürger'

kõrralik pro topelt (körralick 'doppelt')

maa pro ruum (Mah 'Raum'), vrd Taÿwase rhumi sisse (Müller 16001606); Ruum, -i (Göseken 1660) < kasks rûm 'Raum'

noormees pro sell (Nôr Mêhs 'Gesell')

piimapäälne pro mant (Pimepähline 'Schmant')

rõõm (Trôst / Röhm /a 'Trost'), vrd Trost nĩck röÿmu (Müller 1600-1606); Trohft, [trohst]ift (Stahl 1637); troost, -i; Rohst 'trost (solatium)' (Göseken 1660). Vt troost 2. osas

\section{Kokkuvõtteks}

Teadaolevate alamsaksa laenude ja Gutslaffi sõnavara kõrvutamisel sõelale jäänu (214 sõna) osutab, et Gutslaff kasutas saksa märksõnade vastetena alamsaksa laene ligi pooltel juhtudel (103 sõna). Paljud 17. sajandiks eesti keelde ja tollaste autorite teostesse jõudnud alamsaksa laenud Gutslaffi grammatika saksa-eesti sõnastikus ei kajastu. Ta on eelistanud nende asemel võtta eesti vasteks kas (lõunaeesti) omasõna, juba varasema (germaani, balti vm) laenuna omaksvõetu või on tuletanud sõnavaste ise.

Laensõnade keeldetuleku-kasutamise kontekstis torkab silma: 
1) sageli ei pidanudki alamsaksa sõna täitma mingit leksikaalset tühikut, sest võõrsõna ilmus eesti keeles juba olemasoleva(te) sõna(de) kõrvale, nt pott (varem olemas katel ja pada), palk (varem hirs), puur (varem oherdi), kuid sõnavara muutumine järgis ühtlasi elumuutusi, sh uuenenud esemetüüpe ja töövõtteid;

2) alati ei tõrjunud võõrsõnast uudissõna (ja kodunedes laensõna) seniseid murdevariante käibelt, vaid ilmus teiste kõrvale, vrd task $(<$ kasks tasche), tasku $(<\mathrm{rts}$ taska), kalits $(<\mathrm{vn}$ калита), karman $(<$ vn карман), (tengel)pung ( $<$ kasks bunge);

3) paljud alamsaksa laensõnad olid 17. sajandiks käibel põhjaeesti murdekeeles või levisid üle maa (nt kelm, klatt, neer, pärm), mitmed Gutslaffi esitatud sõnavasted pärinesid kitsama levikuga lõunaeesti murdekeelest (nt herits, nilbe, saibass, tsagama, val(l)im);

4) alamsaksa lähtesõna võis eesti keelde anda ka kaks eri sõnakuju, üks ühel, teine teisel pool keelepiiri - vrd lõunaeesti võlss ja põhjaeesti valsk (< kasks falsch 'falsch').

Arvestades asjaolu, et Urvaste hingekarjase Johannes Gutslaffi saksa-eesti sõnastik on ainus 17. sajandil publitseeritud lõunaeesti leksikon, esindab see ühtlasi tolle ajajärgu sõnakasutust. Alamsaksa laenude kontekstist ilmneb, et sõnastiku omasõnavarast pärineb kolmandik lõunaeesti murdekeelest (sh Võru murdest). Selles seoses tundub, et saksa märksõnade eesti vastete seas on omasõnavara osakaal pigem suur kui väike; omasõnade seas tunnukse aga lõunaeesti murdesõnade osakaal olevat pigem väike kui suur. Ladinakeelse põhiteksti ning laiema levikuga eesti murdesõnavara poolest oleks Gutslaffi grammatikal olnud eeldusi leida rakendust ka väljaspool omaaegset tartu kirjakeele ala.

\section{Aadress:}

Jüri Viikberg

Eesti Keele Instituut

Roosikrantsi 6

10119 Tallinn

E-post: viikberg@eki.ee

\section{Kihelkonna- ja murdelühendid}

Aud - Audru, eL - lõunaeesti murded, eP - põhjaeesti murded, Ha - Harjumaa murrakud, Har - Hargla, Hel - Helme, Hi - Hiiumaa murrakud, Hlj - Haljala, Hls - Halliste, I - idamurre, Iis - Iisaku (idamurre), IisK - Iisaku (keskmurre), 
IisR - Iisaku (rannikumurre), Jaa - Jaani, JMd - Järva-Madise, Juu - Juuru, Jõh - Jõhvi, Jä - Järvamaa murrakud, K - keskmurre, Kam - Kambja, Khk Kihelkonna, KJn - Kolga-Jaani, KLõ - keskmurde lõunamurrakud, Kod Kodavere, Koe - Koeru, Krk - Karksi, Krl - Karula, Kse - Karuse, Ksi Kursi, Kuu - Kuusalu (rannikumurre), KuuK - Kuusalu (keskmurre), Käi Käina, L - läänemurre, Lai - Laiuse, Lei - Leivu, Lut - Lutsi, Lä - Läänemaa murrakud, Lüg - Lüganuse, M - Mulgi murre, Mar - Martna, Mih - Mihkli, MMg - Maarja-Magdaleena, Muh - Muhu, Nõo - Nõo, Ote - Otepää, Plt Põltsamaa, Puh - Puhja, Pä - Pärnumaa murrakud, R - kirderannikumurre, Ran - Rannu, Rõn - Rõngu, Rõu - Rõuge, S - saarte murre, Sa - Saaremaa murrakud, Saa - Saarde, San - Sangaste, Se - Setu, SJn - Suure-Jaani, T Tartu murre, TaPõ - Põhja-Tartumaa murrakud, TLä - Lääne-Tartumaa murrakud, Trm - Torma, Trv - Tarvastu, Tõs - Tõstamaa, Urv - Urvaste, V Võru murre, Vai - Vaivara, Vas - Vastseliina, VId - Ida-Võrumaa murrakud, Vig - Vigala, ViK - Virumaa murrakud, Vil - Viljandi, VJg - Viru-Jaagupi, Vll - Valjala, VIPõ - Põhja-Viljandimaa murrakud, VMr - Väike-Maarja, VNg - Viru-Nigula, Võn - Võnnu, Äks - Äksi

\section{Allikad}

Ametivanne $1570=$,Juramentum der Vndudeschen”. Ehasalu et al. Eesti keele vanimad tekstid ja sõnastik, 79. (Tartu Ülikooli eesti keele õppetooli toimetised, 6.) Tartu: Tartu Ülikool.

Awerbach 1589 = „Tunnistus Sigismundus Awerbachile 1589”. Ehasalu et al. Eesti keele vanimad tekstid ja sõnastik, 93-95. (Tartu Ülikooli eesti keele õppetooli toimetised, 6.) Tartu: Tartu Ülikool.

Boierus 1587 = „Laurentius Boieruse käsikiri 1587-1595”. Ehasalu et al. Eesti keele vanimad tekstid ja sõnastik, 89-92. (Tartu Ülikooli eesti keele õppetooli toimetised, 6.) Tartu: Tartu Ülikool.

EES = Eesti etümoloogiasõnaraamat. Iris Metsmägi, Meeli Sedrik, Sven-Eerik Soosaar, koost. ja toim. Iris Metsmägi, peatoim. Tallinn: Eesti Keele Sihtasutus, 2012.

EEW = Julius Mägiste (1982) Estnisches etymologisches Wörterbuch I-XII. Helsinki: Finnisch-Ugrische Gesellschaft.

EKI MK = Eesti Keele Instituudi murdekartoteek.

EKMS = Andrus Saareste (1958-1963) Eesti keele mõisteline sõnaraamat I-IV. Stockholm: Vaba Eesti.

EMS $=$ Eesti murrete sõnaraamat I-V köide $(a-$ maaglema $)$. Tallinn: Eesti Keele Instituut, 1994-2013.

Gutslaff 1648 = Johannes Gutslaff (1998) [1648] Observationes grammaticae circa linguam Esthonicam. Grammatilisi vaatlusi eesti keelest. (Tartu Ülikooli eesti keele õppetooli toimetised, 10.) Tlk., koost. Marju Lepajõe, toim. Jaak Peebo. Tartu: Tartu Ülikool, 1998. 
Gutslaff 1647-1657 = Johannes Gutslaffi piiblitõlge 1647-1657. Koost. Maeve Leivo, Ahti Lohk, Kristiina Ross, Kai Tafenau. Eesti Keele Instituut. Tallinn: Eesti Keele Sihtasutus, 2013.

Göseken 1660 = Valve-Liivi Kingisepp, Kristel Ress, Kai Tafenau. Heinrich Gösekeni grammatika ja sõnastik 350. Tartu: Tartu Ülikool, 2010.

Hinderling, Robert (1981) Die deutsch-estnischen Lehnwortbeziehungen im Rahmen einer europäischen Lehnwortgeographie. Wiesbaden: Otto Harrasowitz.

Koell $1535=$ „Wanradti-Koelli katekismus 1535”. Ehasalu et al. Eesti keele vanimad tekstid ja sõnastik, 65-76. (Tartu Ülikooli eesti keele õppetooli toimetised, 6.) Tartu: Tartu Ülikool.

Koponen, Eino (1998). Eteläviron murteen sanaston alkuperä. Itämerensuomalaista etymologiaa. (Suomalais-Ugrilaisen Seuran Toimituksia 230.) Helsinki.

Kullamaa käsikiri 1524 = „Kullamaa vakuraamat 1524-1532”. Ehasalu et al. Eesti keele vanimad tekstid ja sõnastik, 59-60. (Tartu Ülikooli eesti keele õppetooli toimetised, 6.) Tartu: Tartu Ülikool.

LiiviTalu $1550=$ „Katkend Liivimaa talurahva õigusest”. Ehasalu et al. Eesti keele vanimad tekstid ja sõnastik, 77. (Tartu Ülikooli eesti keele õppetooli toimetised, 6.) Tartu: Tartu Ülikool.

Müller 1600-1606 = Külli Habicht, Valve-Liivi Kingisepp, Urve Pirso, Külli Prillop (2000) Georg Mülleri jutluste sõnastik. (Tartu Ülikooli eesti keele õppetooli toimetised, 12.) Tartu: Tartu Ülikool.

Raag, Raimo (1987) „Mittelniederdeutsche und skandinavische Lehnwörter im Estnischen und Livischen". Sprachkontakt in der Hanse. Aspekte des Sprachausgleichs im Ostsee- und Nordseeraum. Akten des 7. Internationalen Symposions über Sprachkontakt in Europa, Lübeck 1986. P. Sture Ureland, Hg. Tübingen: Max Niemeyer Verlag.

Raun, Alo (1982) Eesti etümoloogiline teatmik. Rooma-Toronto: Maarjamaa.

Rossihnius 1632 = Valve-Liivi Kingisepp, Külli Habicht, Külli Prillop (2002) Joachim Rossihniuse kirikumanuaalide leksika. (Tartu Ülikooli eesti keele õppetooli toimetised, 22.) Tartu: Tartu Ülikool.

SSA = Suomen sanojen alkuperä I-III. Etymologinen sanakirja. (Suomalaisen Kirjallisuuden Seuran toimituksia 556. Kotimaisten Kielten Tutkimuskeskuksen julkaisuja 62.) Helsinki, 1992-2000.

Stahl 1637 = Kikas, Kristel (2001) Mida sisaldab Heinrich Stahli Vocabula? (Tartu Ülikooli eesti keele õppetooli toimetised, 21.) Tartu: Tartu Ülikool.

VMS = Väike murdesõnastik I-II. Toim. Valdek Pall. Eesti NSV TA Keele ja Kirjanduse Instituut. Tallinn: Valgus, 1982, 1989.

Völcker $1585=$ „Johannes Ambrosius Völckeri kirjutised 1585-1590”. Ehasalu et al. Eesti keele vanimad tekstid ja sõnastik, 80-87. (Tartu Ülikooli eesti keele õppetooli toimetised, 6.) Tartu: Tartu Ülikool. 


\title{
Kirjandus
}

Ariste, Paul (1940) Georg Mülleri saksa laensõnad. (Acta et Commentationes Universitatis Tartuensis, B 46.) Tartu: Tartu Ülikool, 1-63.

Ariste, Paul (1963) „Saksa laensõnad Heinrich Stahli eesti keeles”. Emakeele Seltsi aastaraamat (Tallinn) 9, 85-119.

Ehasalu, Epp, Külli Habicht, Valve-Liivi Kingisepp, Jaak Peebo (1997). Eesti keele vanimad tekstid ja sõnastik. (Tartu Ülikooli eesti keele õppetooli toimetised, 6.) Tartu: Tartu Ülikool.

Keem, Hella (1998) „Johannes Gutslaffi grammatika eesti keel ja Urvaste murrak”. Gutslaff, Johannes, Observationes grammaticae circa linguam Esthonicam. Grammatilisi vaatlusi eesti keelest, 317-332. (Tartu Ülikooli eesti keele õppetooli toimetised, 10.) Tlk., koost. Marju Lepajõe. Toim. Jaak Peebo. Tartu: Tartu Ülikool.

Lepajõe, Marju (1998) „Johannes Gutslaffi „Grammatilised vaatlused””. Gutslaff, Johannes, Observationes grammaticae circa linguam Esthonicam. Grammatilisi vaatlusi eesti keelest, 285-316. (Tartu Ülikooli eesti keele õppetooli toimetised, 10.) Tlk., koost. Marju Lepajõe. Toim. Jaak Peebo. Tartu: Tartu Ülikool.

Liin, Helgi (1964) „Alamsaksa laensõnad eesti vanimas kirjakeeles”. Töid eesti filoloogia alalt 1, 32-74. (Tartu Riikliku Ülikooli Toimetised, 162.) Tartu: Tartu Riiklik Ülikool.

Liin, Helgi (1968). „Alamsaksa laensõnadest 16. ja 17. sajandi eesti kirjakeeles”. Emakeele Seltsi aastaraamat (Tallinn) 13 (1967), 47-69.

\begin{abstract}
Jüri Viikberg: About Low German loanwords on the basis of Johannes Gutslaff's grammar. The present paper gives an overview of the Estonian equivalents in the German-Estonian vocabulary of the first South Estonian grammar "Observationes grammaticae circa linguam Esthonicam" (1648), with emphasis on probable Low German loanwords. The entries have been selected and grouped according to which equivalent the author has given them in Estonian: either a Low German loanword or an Estonian word. In the latter case, we have tried to differentiate between dialect (mainly Võru) words and Gutslaff's own word creation. A conclusion is made that Gutslaff's word usage is one of the indicators of how Low German borrowings came into Estonian.
\end{abstract}

Keywords: Low German loanwords, Old Literary Estonian, Literary South Estonian, 17th century, Johannes Gutslaff, language contacts 